\title{
Formulation development and evaluation of carbopol-incorporated mucoadhesive thermoreversible gels of sucralfate for rectal drug delivery
}

Firoz Shaik $^{1}$

ORCID:0000-0002-9925-4144

Raja Sekaran ${ }^{2 *}$

ORCID: 0000-0002-1145-912X

${ }^{1}$ Research scholar, Department of Pharmaceutics, Faculty of Pharmacy, Bhagwant University, Ajmer, Rajasthan, India.

${ }^{2}$ Faculty of Pharmacy, Bhagwant University, Ajmer, Rajasthan, India

Corresponding author:

Firoz Shaik

Research Scholar

Faculty of Pharmacy,

Bhagwant University,

Ajmer - 305004, Rajasthan, India.

Tel: + 91-9703573686

E-mail address: fytopharmshama@gmail.com

Received date : 21.10 .2021

Accepted date : 17.12.2021
DOI: 10.52794/hujpharm.1012883

\section{ABSTRACT}

The present study describes the preparation and evaluation of a Poloxamer 188 (P188)-based thermoreversible gel using Carbopol 934P (C934P) as a mucoadhesive polymer of Sucralfate for enhancing the bioavailability and to avoid the first-pass metabolism. Eight formulations (F1-F8) were prepared using cold method. The prepared gels were characterized by $\mathrm{pH}$, drug content, spreadability, mucoadhesive force, gelation temperature, and drug release profile. Thermoreversibility of P188/C934P gel was demonstrated by rheological studies. The drug-polymer compatibility was studied using Fourier transform infrared (FTIR). The incorporation of carbopol into P188 gel also reduced the amounts of drug released from the gel formulations.

FT-IR studies revealed that there are no interactions between the drug and polymers. Drug content of gels was estimated and the results were found to be satisfactory. In vitro dissolution studies revealed a good drug release from the gels. The drug release was higher in formulations F5 and F6 and lower in F4, F7, and F8 formulations. These findings suggested that developed thermoreversible gels could be used as promising dosage forms to rectal drug delivery for prolonged periods in the management of hemorrhoids.

KEYWORDS: Rectal, Drug release, Mucoadhesive, Thermoreversible gel, Sucralfate. 


\section{INTRODUCTION}

The concept of mucosal adhesion or mucoadhesive was introduced into controlled drug delivery area in the early 1980 s, which is a major part of a novel drug delivery system in recent era some of the potential sites for attachment of any mucoadhesive system utilize the property of adhesion of certain water-soluble polymers to buccal cavity, nasal cavity, eyes, vagina, rectal area, sublingual route, and gastrointestinal area [1].

The utilization of mucoadhesive system is essential to maintain an intimate and prolonged contact of the formulation with the rectal mucosa allowing a longer duration for absorption. Thermoreversibility is a property of certain substances to be reversed when exposed to heat. Such substances form a gel when cooled and return to a viscous fluid state when exposed to heat. [2].

Rectal administration uses the rectum as a route of administration for medication and other fluids, which are absorbed by the rectum blood vessels, a drug that is administered rectally will have a faster onset of action [3]. Rectal route offers a useful, non-invasive alternative route of administration when local or systemic effect is intended. The rectum provides a relatively constant environment for drug delivery that allows a persistent steady-state concentration of drug in plasma and partially avoids gastrointestinal absorption difficulties and hepatic first-pass metabolism [4]. Hence the present study was carried out to formulate and analyze mucoadhesive thermoreversible gels of sucralfate for rectal drug delivery and also to improve the bioavailability of the drug as compared with oral route.

Hemorrhoids are enlarged and swollen blood vessels but are found in the lower part of the rectum and anus [5]. Internal hemorrhoids grow within the rectum that is above the pectinate line, a boundary that divides the upper two-thirds of the anal canal from the lower one-third of the said area. Internal hemorrhoids are encased in a lining called mucosa that is not sensitive to touch, pain, stretching, or temperature [6].

Sucralfate is a medication used to treat duodenal ulcers, epithelial wounds, chemotherapy-induced mucositis, radiation proctitis, ulcers in Behcet disease, and burn wounds. Sucralfate exhibits its action by forming a protective layer, increasing bicarbonate production, exhibiting anti-peptic effects, promoting tissue growth, regeneration, and repair [7-9].

\section{MATERIALS AND METHODS}

\section{Materials}

Sucralfate was obtained as a gift sample from Strides Arcolab, Bangalore (Purity 97\%). Poloxamer 188 (P188) and Carbopol 934P (C934P) were purchased from Sigma-Aldrich. HPMC K4M was gifted by Colorcon Asia Pvt. Ltd., Goa India. All other chemicals and reagents used in the study were of analytical grade.

\section{Preparation of formulations}

Experimental runs for optimization of formulation with the help of $2^{3}$ factorial designs were designed [10]. Design Expert program 6.0.6 (Stat-Ease Inc. Minneapolis, MN) was used to create formulations. Formulations were optimized using full factorial design. In situ rectal gel was prepared by the cold method [11]. As shown in Table 1, P188 was dissolved in DDW (de-ionized distilled water) including drug $(1 \% \mathrm{w} / \mathrm{v})$ at room temperature, and it was stored at $4^{\circ} \mathrm{C}$ for complete solubilization of P188. Carbopol solubilized in DDW, HPMC K4M and other mucoadhesive polymers were then slowly added to the prepared solution with continuous agitation at $4{ }^{\circ} \mathrm{C}$ and was kept for $24 \mathrm{~h}$ before their use. The composition of developed gel formulations is summarized in Table 1.

\section{Determination of $\mathrm{pH}$}

The $\mathrm{pH}$ of various gel formulations was determined using digital $\mathrm{pH}$ meter (Equiptronics, Model EQ610). $1 \mathrm{~g}$ of in situ gel was dissolved in $100 \mathrm{ml}$ distilled water and stored for $2 \mathrm{~h}$. The measurement of $\mathrm{pH}$ of each formulation was done in triplicate [12].

\section{Visual appearance and clarity}

The clarity and appearance of various developed formulations were determined by visual inspection under black and white background.

\section{Drug content}

It is used to measure the content uniformity. $1 \mathrm{ml}$ of formulation was taken and it was added to $10 \mathrm{ml}$ volumetric flask, and then, the volume was made 
Table 1. The composition of the gels.

\begin{tabular}{|c|c|c|c|c|c|c|c|c|c|}
\hline S.No. & Ingredients & F1 & $\mathbf{F} 2$ & F3 & F4 & F5 & F6 & F7 & F8 \\
\hline 1 & Sucralfate $(\% \mathrm{w} / \mathrm{v})$ & 1 & 1 & 1 & 1 & 1 & 1 & 1 & 1 \\
\hline 2 & Poloxomer $188(\% \mathrm{w} / \mathrm{v})$ & 20 & 5 & 5 & 5 & 20 & 20 & 20 & 5 \\
\hline 3 & Carbopol 934 (mg) & 5 & 5 & 5 & 0 & 5 & 0 & 0 & 0 \\
\hline 4 & HPMC K4M (mg) & 15 & 5 & 15 & 15 & 5 & 5 & 15 & 5 \\
\hline 5 & Methyl Cellulose (mg) & 5 & 15 & 5 & 15 & 5 & 15 & 5 & 15 \\
\hline 6 & Hydroxy Ethyl cellulose (mg) & 5 & 15 & 15 & 5 & 15 & 5 & 5 & 15 \\
\hline 7 & Poly vinyl Pyrrolidine (mg) & 5 & 10 & 5 & 0 & 0 & 0 & 5 & 5 \\
\hline 8 & Distilled Water & $\begin{array}{l}\text { Quantity } \\
\text { Suffficient } \\
\text { (Upto } 100 \mathrm{ml} \text { ) }\end{array}$ & & & & & & & \\
\hline
\end{tabular}

with distilled water and then further dilutions were made and ultraviolet (UV) absorbance (Shimadzu UV Vis Spectrophotometer, UV 1800) was taken at $281 \mathrm{~nm}$. The blank was prepared by preparing formulation without drug, and then, $1 \mathrm{ml}$ of sample was taken and it was added to $10 \mathrm{ml}$ volumetric flask and serial dilutions were made with distilled water, and then, the UV measurements were taken. The values obtained were used to calculate the concentration of drug in formulation [13]. The procedure was done in triplicate in order to ensure that the drug is homogeneously distributed in the gel. Drug content was calculated by following formula;

Drug content $=($ Absorbance $/$ Slope $) \times$ Dilution factor $\times(1 / 1000)$

\section{Spreadability}

For the determination of spreadability, excess of sample was applied in between two glass slides and was compressed to uniform thickness by placing $200 \mathrm{~g}$ weight for $5 \mathrm{~min}$ weight was added to the pan. The time in which the upper glass slide and moves over to the lower plate was taken as measure of spreadability [14].

Where, $\mathrm{M}=$ Weight tide to upper slide, $\mathrm{L}=$ Length moved on the glass slide, $\mathrm{T}=$ Time taken.

\section{Gelation temperature}

Gelation temperature was determined using the tube tilting method [15]. Gelling temperature refers to the temperature when the meniscus of the formulation would no longer move upon slanting the test tubes at $90^{\circ} .10 \mathrm{ml}$ aliquot of gel was transferred to test tubes, immersed in a water bath at $4^{\circ}$ and sealed with aluminum foil. The temperature of water bath was increased gradually and left to equilibrate for $5 \mathrm{~min}$ at each new setting. The samples were then examined for gelation, which were said to have occurred when the meniscus would no longer move upon tilting through $90^{\circ}$. For each solution, the temperature at which a solid gel formed was measured using a calibrated thermometer. All gelation temperature results are the mean of $\mathrm{n}=3$ experiments.

\section{Viscosity studies}

Viscosity of the prepared formulations was measured by using Brookfield Viscometer. The suitable spindle was lowered perpendicularly into the fixed volume of gel which was to be measured. The spindle was rotated at varying speeds and the suitable speed was selected. The temperature was increased initially above $37-38^{\circ} \mathrm{C}$ and then the viscosity was measured as the system was allowed to cool gradually [16].

\section{Determination of mucoadhesive force}

A section of skin membrane (i.e., obtained from rats) (IAEC approval No. SVCP/IAEC/I-07/MAR2021) and instantly fixed with mucosal side out on to each class vial using rubber band. The vial with membrane was connected to the balance in inverted position while first vial was placed on a height adjustable pan. The area of tissue surface exposed out is $0.785 \mathrm{~cm}^{2}$. Then a height of second vial was so adjusted that the mucosal surfaces of both vials come in intimate contact. Two minutes time of contact was 
given. Then weight was kept rising in pan until vials get detached. Mucoadhesive force was the minimum weight required to detach to vials [17].

Where $\mathrm{m}$ is the weight added to the balance in grams, $\mathrm{g}$ is the acceleration due to gravity taken as $980 \mathrm{~cm} /$ $\mathrm{s}^{2}$ and $\mathrm{A}$ is the area of the exposed tissue surface.

\section{In Vitro Drug Release Studies}

The in vitro release of Sucralfate from the formulation was studied through egg membrane using modified apparatus. The egg membrane previously soaked for $17 \mathrm{hr}$ in phosphate buffer (pH 7.4). Then the membrane was tied to one end of specially designed glass cylinder. $1 \mathrm{ml}$ of formulation was accurately placed into this assembly. The cylinder was attached to a stand and suspended in $50 \mathrm{ml}$ of dissolution medium maintained at $37 \pm 1^{\circ} \mathrm{C}$ so that the membrane just touched the receptor medium surface. The diffusion medium was stirred at low speed using magnetic stirrer. $5 \mathrm{ml}$ of volume was withdrawn at $40 \mathrm{~min}$ time intervals and replaced by an equal volume of receptor medium. The aliquots were suitably diluted with the receptor medium and analyzed by UV-Visible Spectrophotometer (Shimadzu UV Vis Spectrophotometer, UV 1800) at $281 \mathrm{~nm}$. The values had been subjected to the calculation of release profiles of the drug fitting the best model [18].

\section{Statistical data analysis}

The analysis of statistical data was obtained with the Student's t-test by $\mathrm{P}<0.05$ as the minimal level of significance.

\section{RESULTS AND DISCUSSION}

The Fourier transform infrared (FT-IR) spectra of Sucralfate, poloxamer, carbopol, and Sucralfate loaded in gel formulation are depicted in Fig. 1-4, respectively. FTIR spectroscopic study results discovered that no new peak appearance or disappearance of existing peaks, discarding any chemical interaction probability among drug and polymer used. Thus, IR spectroscopy results depicted that Sucralfate was compatible with selected polymers.

\section{Visual Appearance, $\mathrm{pH}$ and Drug Content}

The surface $\mathrm{pH}$ of the rectal gels was determined to optimize the drug permeation. All tested formulations showed a $\mathrm{pH}$ range from $6.5 \pm 0.32$ to $6.8 \pm 0.35$ which is acceptable for administration in the rectal cavity. Results are shown in Table 2. The drug content was found to be in acceptable range for all the formulations. Percent drug content in all formulations was in the range $95.2 \pm 0.82$ to $99.3 \pm 0.02 \%$ indicating uniform distribution of drug (Figure 5). The results were shown in Table 2. All tested formula-

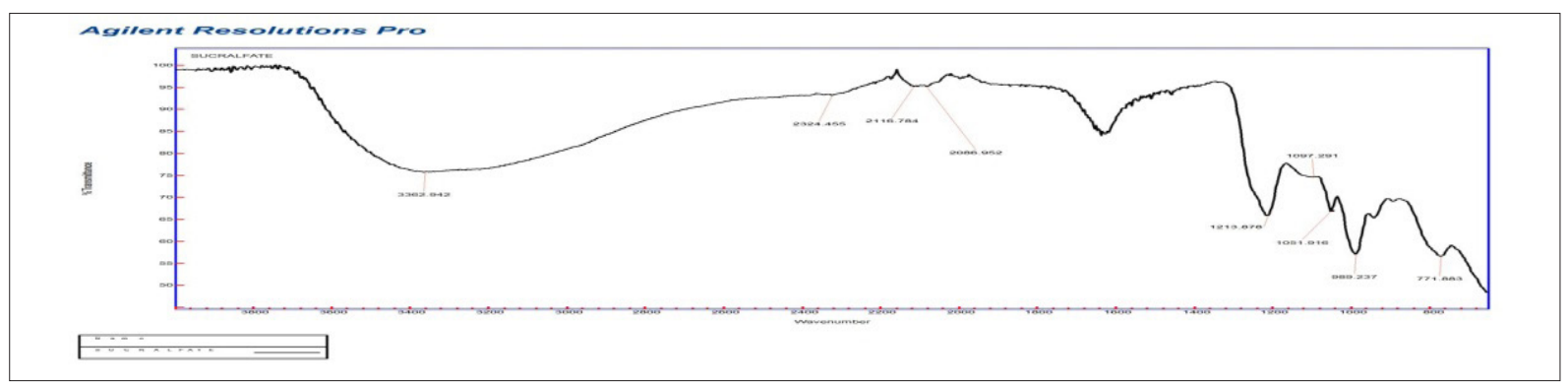

\section{FT-IR Spectrum of Sucralfate pure drug} corresponding wave numbers in the Spectrum with respect to its structure
Characteristic Peaks and its

\begin{tabular}{l|l}
\hline$-\mathrm{OH}$ stretch & $3362 \mathrm{~cm}^{-1}$ \\
\hline $\mathrm{C}-\mathrm{O}$ stretch & $1213 \mathrm{~cm}^{-1}$ \\
\hline $\mathrm{S}=\mathrm{O}$ stretch & $1051 \mathrm{~cm}^{-1}$ \\
\hline hatic $\mathrm{C}-\mathrm{H}$ stretch & $2324 \mathrm{~cm}^{-1}$
\end{tabular}

Figure 1. Fourier transform infrared spectra of drug (Sucralfate) 


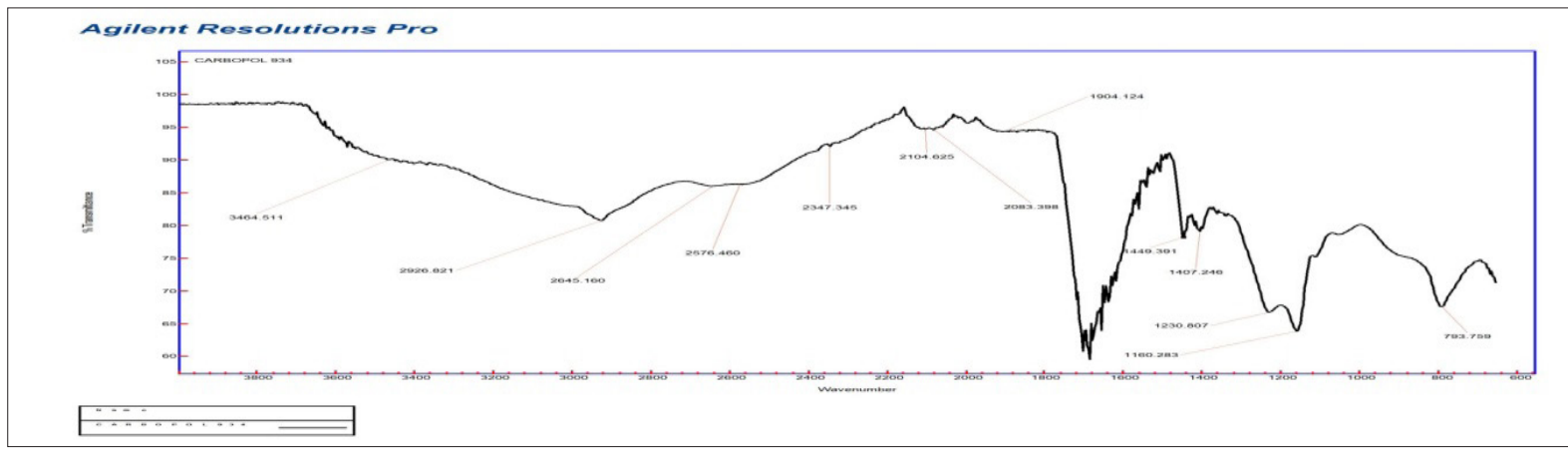

\section{FT-IR Spectrum of Carbopol 934 polymer}

Characteristic Peaks and its corresponding wave numbers in the Spectrum with respect to its structure
Acidic $\mathrm{C}=\mathrm{O}$ stretch

Acidic $-\mathrm{OH}$ stretch

Aliphatic C-H stretch
$1904 \mathrm{~cm}^{-1}$

$3464 \mathrm{~cm}^{-1}$

$2926 \mathrm{~cm}^{-1}$

Figure 2. Fourier transform infrared spectra of polymer (carbopol)

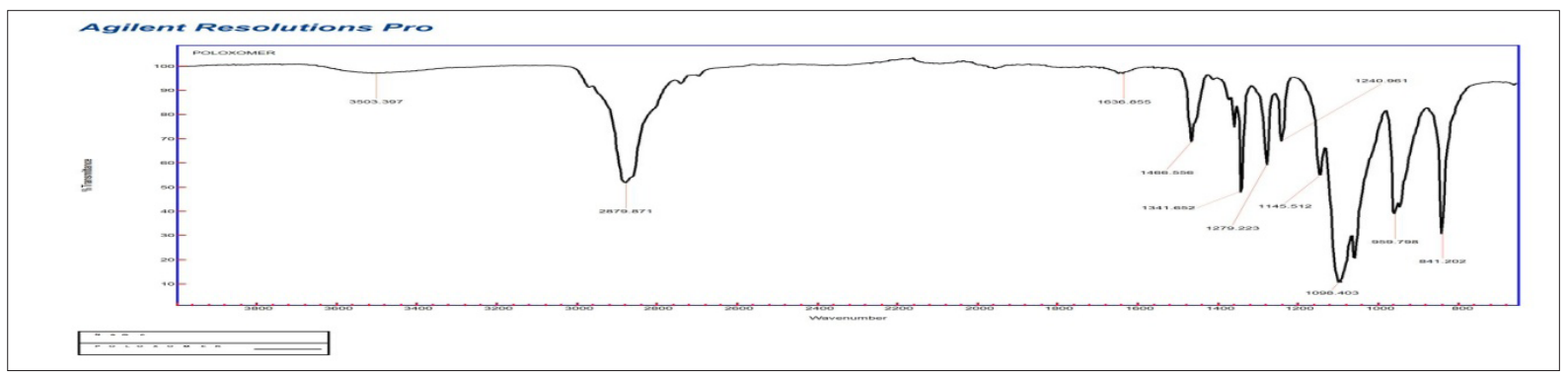

\section{FT-IR Spectrum of Polaxomer 188 polymer}

Characteristic Peaks and its corresponding wave numbers in the Spectrum with respect to its structure
C-O stretch

Aliphatic C-H stretch

OH stretch
$1145 \mathrm{~cm}^{-1}$

$2879 \mathrm{~cm}^{-1}$

$3503 \mathrm{~cm}^{-1}$

Figure 3. Fourier transform infrared spectra of polymer (Polaxomer 188 polymer)

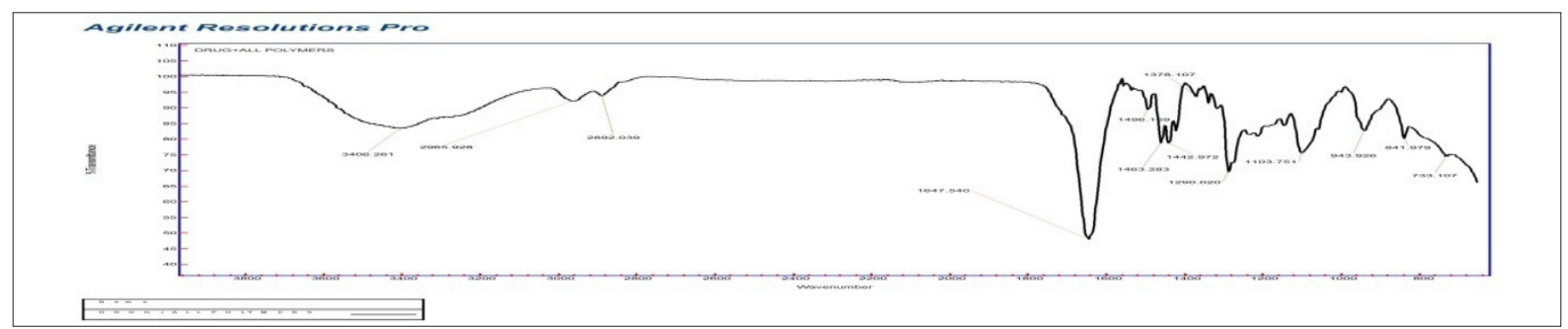

\begin{tabular}{|c|c|c|}
\hline FT-IR Spect & ff Drug \& Polym & ixture \\
\hline \multirow{7}{*}{$\begin{array}{l}\text { Characteristic Peaks and its } \\
\text { corresponding wave numbers } \\
\text { in the Spectrum with respect } \\
\text { to its structure }\end{array}$} & OH stretch & $3406 \mathrm{~cm}^{-1}$ \\
\hline & C-O stretch & $1103 \mathrm{~cm}^{-1}$ \\
\hline & $\mathrm{S}=\mathrm{O}$ stretch & $1378 \mathrm{~cm}^{-1}$ \\
\hline & Aliphatic C-H stretch & $2892 \mathrm{~cm}^{-1}$ \\
\hline & C-N stretch & $1290 \mathrm{~cm}^{-1}$ \\
\hline & Acidic $\mathrm{C}=\mathrm{O}$ stretch & $1647 \mathrm{~cm}^{-1}$ \\
\hline & Acidic - OHI stretch & $2965 \mathrm{~cm}^{-1}$ \\
\hline
\end{tabular}

Figure 4. Fourier transform infrared for Sucralfate + polymers 
Table 2. Appearance, \% Drug content \& pH of Mucoadhesive Thermo reversible Gels

\begin{tabular}{llll}
\hline Formulation Code & Appearance & \% Drug content* \pm S.D & pH* \pm S.D \\
\hline F1 & Transparent, Colourless & $99.3 \pm 0.02$ & $6.5 \pm 0.33$ \\
\hline F2 & Transparent, Colourless & $96.4 \pm 0.01$ & $6.5 \pm 0.31$ \\
\hline F3 & Transparent, Colourless & $98.3 \pm 0.03$ & $6.7 \pm 0.32$ \\
\hline F4 & Transparent, Colourless & $98.1 \pm 0.05$ & $6.8 \pm 0.35$ \\
\hline F5 & Transparent, Colourless & $97.3 \pm 0.07$ & $6.8 \pm 0.34$ \\
\hline F6 & Transparent, Colourless & $96.1 \pm 0.21$ & $6.4 \pm 0.22$ \\
\hline F8 & Transparent, Colourless & $98.2 \pm 0.54$ & $6.7 \pm 0.45$ \\
\hline & Transparent, Colourless & $95.2 \pm 0.82$ & $6.5 \pm 0.68$ \\
\hline
\end{tabular}

tions were homogenous, transparent and colorless. The results are given in Table 2 .

\section{S.D $=$ Standard deviation}

* Each result is the mean of three determinations \pm S.D

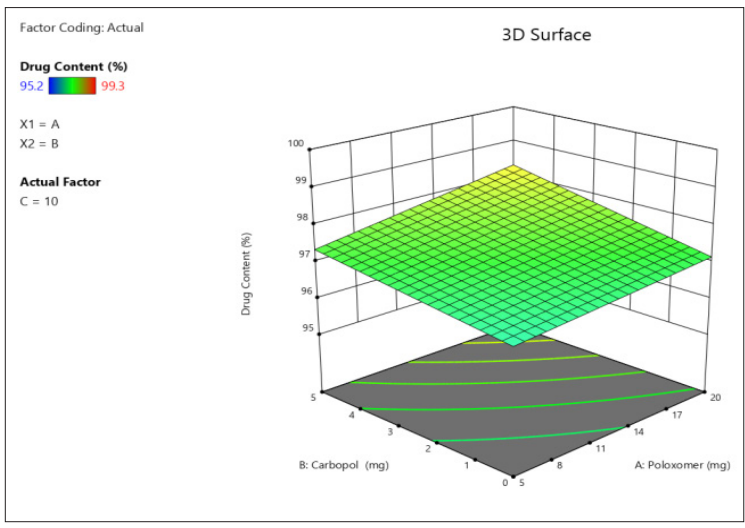

Figure 5. Drug Content in formulated gels

\section{Gelation temperature, Spreadability, Viscosity and Mucoadhesive strength}

The gelation temperature is the criteria for analyzing the properties of a thermo reversible gel. The gelation temperature corresponds to the temperature at which the solution converts to gel. All the formulations exist as liquids at $20.0^{\circ} \mathrm{C}$. Gelation temperature for all the eight formulations was in the range of $30.9 \pm 0.45-37.3 \pm 0.28^{\circ} \mathbf{C}$. The results were given in Table $3 \&$ Figure 7 . The mucoadhesive strength of the prepared gels was significantly $(p<0.05)$ affected by polymer type and it was found that the mucoadhesive strength was significantly $(p<0.05)$ increased

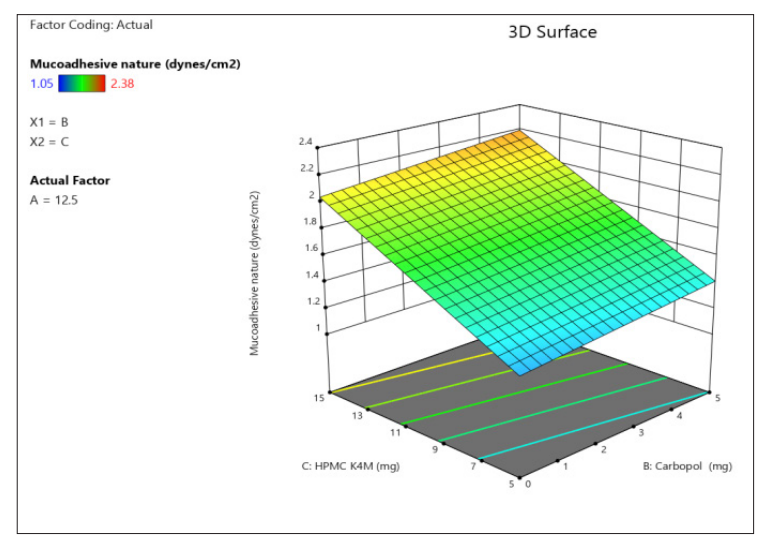

Figure 6. Mucoadhesive Nature of formulated gels

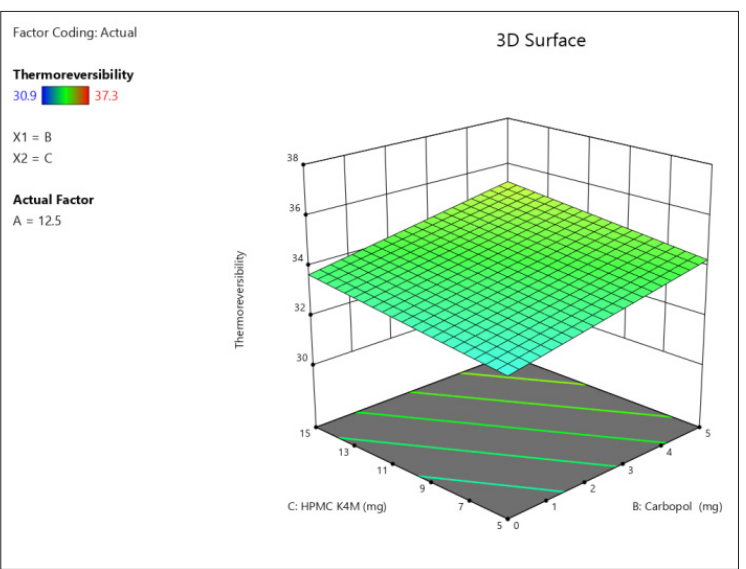

Figure 7. Thermoreversibility of formulated gels

by increasing the polymer concentration (F1, F4 and F7) compared with other formulations (F2, F3, F5, F6 and F8) (Figure 6). The spreadability of the prepared gels was significantly $(\mathrm{p}<0.05)$ decreased as the polymer concentration increased (F1, F4 and F7) compared with other formulations (F2, F3, F5, F6 and F8) (Figure 9). The viscosity of mucoadhesive 


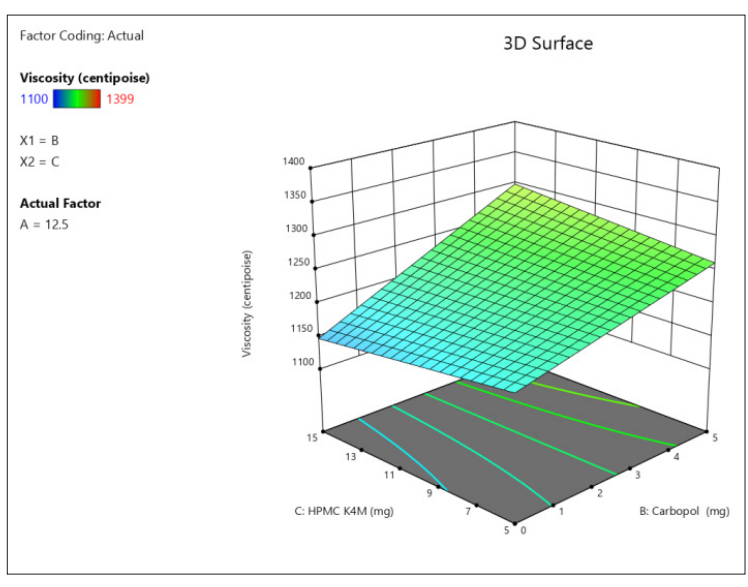

Figure 8. Viscosity of formulated gels

gels is expected to affect their retention \& spreading at the rectum. Higher viscosities would minimize the problem of seepage of the product which can cause discomfort to the patient. The viscosity ranges of all formulations are $1103 \pm 0.56-1399 \pm 0.51$ centipoises (Cp) at $25^{\circ}$ C. Results were shown in Table 3 \& Figure 8 .

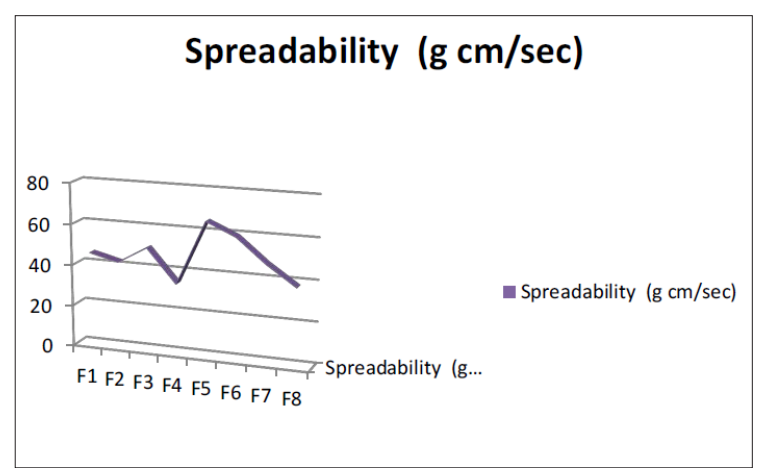

Figure 9. Spreadability of formulated gels

\section{In vitro Drug release Studies:}

In vitro drug release profiles were showed in Figure 10. From the results obtained, it was concluded that as the concentration of polymers increased, there was a decrease in the drug release rate seen. Increase in concentration of polymer causes increase in viscosity of gel layer with longer diffusional path and this could cause reduction in the drug release which may be due to reduction in the water channel number,

Table 3. Gelation temperature, mucoadhesive force, spreadability and viscosity of thermo reversible Gels

\begin{tabular}{|c|c|c|c|c|}
\hline Formulation Code & $\begin{array}{l}\text { Mucoadhesive nature } \\
\left(\text { dynes } / \mathrm{cm}^{2}\right)\end{array}$ & $\begin{array}{l}\text { Thermoreversibility (Gelation } \\
\text { Temparature }^{\circ} \mathrm{C} \text { ) }\end{array}$ & $\begin{array}{l}\text { Viscosity } \\
\text { (Centipoise) }\end{array}$ & $\begin{array}{l}\text { Spreadability } \\
\text { (g cm/sec) }\end{array}$ \\
\hline $\mathrm{F} 1$ & $2.38 \pm 0.22$ & $37.3 \pm 0.28$ & $1399 \pm 0.51$ & $45.74 \pm 0.33$ \\
\hline $\mathrm{F} 2$ & $1.23 \pm 0.35$ & $32.4 \pm 0.35$ & $1185 \pm 0.14$ & $42.24 \pm 0.12$ \\
\hline F3 & $1.95 \pm 0.41$ & $33.2 \pm 0.62$ & $1215 \pm 0.36$ & $50.47 \pm 0.58$ \\
\hline F4 & $2.02 \pm 0.21$ & $31.5 \pm 0.18$ & $1100 \pm 0.55$ & $34.23 \pm 0.17$ \\
\hline F5 & $1.65 \pm 0.14$ & $36.2 \pm 0.11$ & $1323 \pm 0.23$ & $65.45 \pm 0.66$ \\
\hline F6 & $1.41 \pm 0.29$ & $34.5 \pm 0.25$ & $1250 \pm 0.25$ & $59.23 \pm 0.15$ \\
\hline F7 & $2.12 \pm 0.11$ & $35.9 \pm 0.69$ & $1210 \pm 0.11$ & $47.54 \pm 0.23$ \\
\hline F8 & $1.05 \pm 0.58$ & $30.9 \pm 0.45$ & $1103 \pm 0.56$ & $37.89 \pm 0.11$ \\
\hline
\end{tabular}

Table 4. Comparative In vitro drug release studies

\begin{tabular}{|c|c|c|c|c|c|c|c|c|c|}
\hline \multirow{2}{*}{ S.No } & \multirow{2}{*}{$\begin{array}{l}\text { Time } \\
\text { (mins) }\end{array}$} & \multicolumn{8}{|c|}{ Drug release $*(\%) \pm$ S.D } \\
\hline & & F1 & F2 & F3 & F4 & F5 & F6 & F7 & F8 \\
\hline 1 & 40 & $25.32 \pm 0.23$ & $59.73 \pm 0.47$ & $18.55 \pm 0.29$ & $18.23 \pm 0.29$ & $21.19 \pm 0.29$ & $19.22 \pm 0.22$ & $20.25 \pm 0.32$ & $18.45 \pm 0.28$ \\
\hline 2 & 80 & $32.65 \pm 0.04$ & $61.17 \pm 0.32$ & $28.65 \pm 0.21$ & $27.25 \pm 0.22$ & $42.09 \pm 0.24$ & $31.04 \pm 0.51$ & $32.85 \pm 0.11$ & $28.34 \pm 0.21$ \\
\hline 3 & 120 & $60.25 \pm 0.07$ & $70.91 \pm 0.50$ & $38.85 \pm 0.33$ & $37.45 \pm 0.33$ & $55.12 \pm 0.35$ & $79.82 \pm 0.22$ & $62.56 \pm 0.25$ & $42.64 \pm 0.24$ \\
\hline 4 & 160 & $71.37 \pm 0.16$ & $72.55 \pm 0.50$ & $70.95 \pm 0.52$ & $60.45 \pm 0.15$ & $89.04 \pm 0.40$ & $82.89 \pm 0.33$ & $75.88 \pm 0.81$ & $71.22 \pm 0.52$ \\
\hline 5 & 200 & $89.38 \pm 0.22$ & $90.25 \pm 0.45$ & $87.58 \pm 0.35$ & $84.78 \pm 0.11$ & $99.38 \pm 0.21$ & $92.58 \pm 0.25$ & $85.45 \pm 0.66$ & $86.14 \pm 0.55$ \\
\hline
\end{tabular}

$\mathrm{S} . \mathrm{D}=$ Standard deviation 


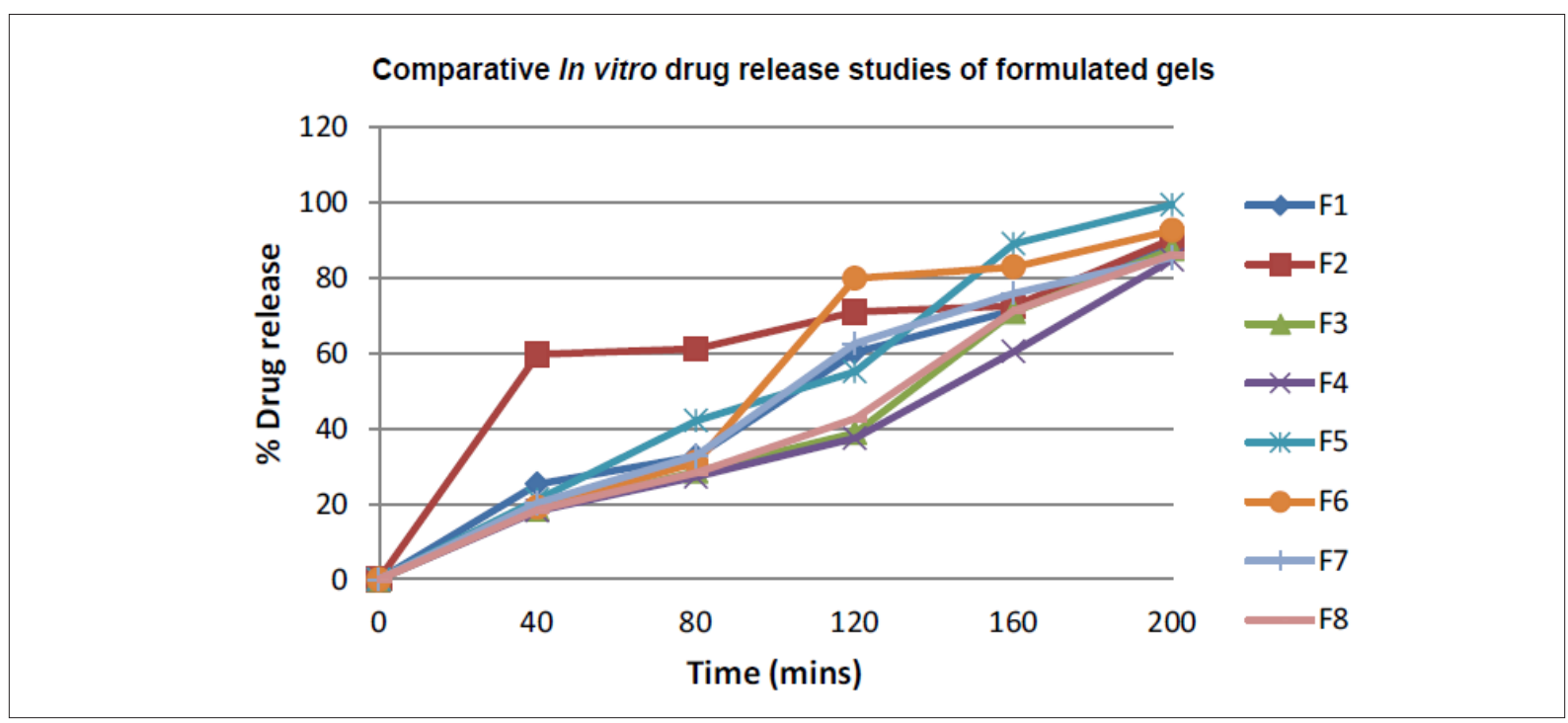

Figure 10. Comparative In vitro drug release studies of formulated gels

dimensions and increase in the size of micelles in the gel structure. Formulations containing carbopol 934P showed faster drug release because of its anionic nature and are reported to demonstrate permeation enhancing properties.

Sucralfate is an oral "anti-ulcer" and gastrointestinal drug. Sucralfate is used as a topical drug for the healing of several types of epithelial wounds such as ulcers, inflammatory dermatitis, mucositis and burn wounds. Sucralfate has also been shown to have antibacterial activity. The present work is an attempt to formulate the drug in the form of mucoadhesive thermoreversible rectal gel. Estimation of sucralfate was carried out by UV spectroscopy at $281 \mathrm{~nm}$ in distilled water. Poloxamer acts as thermoreversible polymer, carbopol acts as good mucoadhesive polymer, and methylparaben acts as preservative. The prepared gels were evaluated for their physicochemical parameters such as $\mathrm{pH}$, drug content, spreadability, mucoadhesive force, gelation temperature, and viscosity studies. FT-IR studies reveal that there were no interactions between drug and polymers. Viscosity studies showed that as the concentration of the polymer increased, there was a corresponding increase in the viscosity. All the formulations appeared to have good mucoadhesive strength. This may be due to the fact that increasing the polymer concentration may provide more adhesive sites and polymer chains for interpenetration with mucin, resulting consequently in enhancing of mucoadhesive strength [19]. The spreadability of the prepared gels was significantly $(\mathrm{p}<0.05)$ decreased, this is due to the fact that an increase in polymer concentration increases the repulsion between chains, increases the cross-linking between chains, and reduces the spreadability [20, 21]. The drug content of gels was estimated and the results were found to be satisfactory. In vitro dissolution studies revealed a good drug release from the gels. It is following diffusion release with Non-Fickian model release. It was found that the drug release was sustained as the polymer concentration increases in the formulation which indicates that the drug release from gels depends on the polymer ratio.

\section{CONCLUSION}

A P188-based thermoreversible gel containing C934P (for mucoadhesiveness) was prepared for rectal delivery of sucralfate. The thermoreversibility of P188/C934P gel was verified by various studies. According to the results of in vitro drug release studies and depending on the gelation temperature, mucoadhesive force, viscosity, and spreadability, the formulations F4 and F7 showed a significant decrease in drug release rate in vitro after $3 \mathrm{~h}$. All of these results revealed that developed thermoreversible gel can be a promising rectal dosage form for the treatment of hemorrhoids and could be subjected for further clinical studies. 


\section{ACKNOWLEDGMENTS}

The authors express deep gratitude to Strides Arcolab, Bangalore, for providing the gift sample of the drug Sucralfate. The authors are also immensely grateful to Sree Vidyanikethan College of Pharmacy, A. Rangampet, for providing all the facilities required to carry out the research work.

\section{CONFLICTS OF INTEREST}

Authors declare that there are no conflicts of interest.

\section{REFERENCES}

1. Gonjari ID, Hosmani AH, Karmarkar AB, Godage AS, Kadam SB, Dhabale PN, et al: Formulation and evaluation of in situ gelling thermoreversible mucoadhesive gel of fluconazole. Drug Discov Ther, 3, 6-9 (2009).

2. Sheeba JM, Sreeja C, Anoop KR : Thermo reversible mucoadhesive gel for nasal delivery of antihypertensive drug. Int $\mathrm{J}$ Pharm Sci Rev Res, 21, 57-63 (2013).

3. Elhady A, Seham S, Naheed DM, Gehanne AS, Noha MZ. : Development of in situ gelling and mucoadhesive mebeverine hydrochloride solution for rectal administration. Saudi Pharm J, 11, 8 (2003)

4. El-Leithy ES, Shaker DS, Ghorab MK, Abdel-Rashid RS. : Evaluation of mucoadhesive hydrogels loaded with diclofenac sodium-chitosan microspheres for rectal administration. AAPS PharmSciTech, 11, 1695-702 (2010).

5. Anmol C, Rajdeep S, Agarwal PN. : Management of hemorrhoids. Ind JClin Pract, 25, 577-80 (2014).

6. Rahimi R, Abdollahi M.: A systemic review of the topical drugs for post hemorrhoidectomy pain. Int $\mathrm{J}$ Pharmacol, 8, 628-637 (2012)

7. Kudaravalli P, John S. Sucralfate. [Updated 2021 Jul 19]. In: StatPearls [Internet]. Treasure Island (FL): StatPearls Publishing; 2021 Jan - Available from: https://www.ncbi.nlm.nih. gov/ books/NBK551527/

8. Ala S, Saeedi M, Eshghi F Rafati M, Hejazi V, Hadianamrei R. : Efficacy of $10 \%$ sucralfate ointment in the reduction of acute postoperative pain after open hemorrhoidectomy: a prospective double-blind, randomized, placebo-controlled trial. World J Surg, 37(1), 233-238 (2013).
9. Gupta PJ, Heda PS, Kalaskar S, Tamaskar VP. : Topical sucralfate decreases pain after hemorrhoidectomy and improves healing: a randomized, blinded, controlled study. Dis Colon Rectum, 51(2), 231-234 (2008).

10. Nahla S. Barakat.: In vitro and In vivo characteristics of a Thermogelling rectal Delivery system of Etodolac. AAPS Pharm Sci Tech., 10(3), 724 (2009).

11. Cho HJ, Balakrishnan P, Park EK, Song KW, Hong SS, Jang TY, et al. : Poloxamer/cyclodextrin/chitosan-based thermoreversible gel for intranasal delivery of fexofenadine hydrochloride. J Pharm Sci, 100, 681-91 (2011).

12. Kumar MV, Aravindram AS, Rohitash K, Gowda DV, Parjanya K. Formulation and evaluation of in-situ gel of bromhexine hydrochloride for nasal delivery. Der Pharmacia Sinica, 3, 699-707 (2012).

13. Prabhakar AN, Mallapa DP, Panchaxari GA, Paresh M. : Formulation and characterization of tapentadol loaded emulgel for topical application. Ind J Pharm Educ Res, 51, 525-35 (2017).

14. Joshu AJ, Kumar AA, Verjina CU, Vasudevan DT, Saritha A. : Formulation and evaluation of antiaging phytosomal gel. Asiam J Pharm Clin Res, 3, 409-22 (2018).

15. Patil PR, Salve VK, Thorat U, Shahi SR. : Formulation and evaluation of ion-sensitive in-Situ nasal gel of zolmitriptan. Int J Pharm Pharm Sci, 7, 47886 (2015).

16. Meenakshi P, Thakkar H, Kasture PV. : Preparation and evaluation of thermoreversible formulations of flunarizine hydrochloride for nasal delivery. Int J Pharm Pharm Sci, 2, 116-20 (2010).

17. Bagul U, Gujar K, Dhat S, Aphale S, Bhavsar M. : In vitro study of mucoadhesive strength of polymers for mucoadhesive drug delivery systems. Int J Curr Pharm Res, 1, 42-6 (2009).

18. Bhupen K, Kritika S, Bansmita K : Development and characterization of mucoadhesive microsphere loaded intranasal gel of venlafaxine $\mathrm{HCl}$. Asian J Pharm Clin Res, 3 Suppl 9, 139-44 (2016).

19. Umme H, Shivakumar HG. : Development of miconazole nitrate thermo sensitive bioadhesive vaginal gel for vaginal candidiasis. Am J Adv Drug Deliv, 1, 358-68 (2013).

20. Contreras MD, Sanchez R.: Application of a factorial design to the study of the flow behavior, spreadability and transparency of a carbopol ETD 2020 gel. Int J Pharm, 234, 149-57 (2002).

21. Firoz S, Padmini K, et al.: Formulation development and evaluation of carbopol-incorporated thermoreversible gels of pseudoephedrine for rectal drug delivery. Asian Journal of Pharmaceutical and Clinical Research, 12(5), 231-5 (2019). 